\title{
SERVIÇO SOCIAL E TRABALHO DA(O) ASSISTENTE SOCIAL: REVISITANDO O DEBATE HISTÓRICO-CRÍTICO*
}

\author{
María Fernanda Escurra \\ Marilda Villela Iamamoto
}

\begin{abstract}
Tão logo o trabalho na sua forma imediata deixa de ser a grande fonte de riqueza, o tempo de trabalho deixa, e tem de deixar, de ser a sua medida e, em consequência, o valor de troca deixa de ser [a medida] do valor de uso. O trabalho excedente da massa deixa de ser condição para o desenvolvimento da riqueza geral, assim como o não trabalho dos poucos deixa de ser condição do desenvolvimento das forças gerais do cérebro humano. Com isso, desmorona a produção baseada no valor de troca, o próprio processo de produção material imediato é despido da forma da precariedade e contradição. [Dá-se] o livre desenvolvimento das individualidades e, em consequência, a redução do tempo de trabalho necessário da sociedade como um todo a um mínimo, que corresponde então à formação artística, científica etc. dos indivíduos por meio do tempo liberado e dos meios criados para todos eles.
\end{abstract}

Karl Marx - Grundrisse (2011 p. 588).

\section{Diretrizes Curriculares de 1996: "questão social" e tra- balho}

Revisitar o debate histórico crítico do Serviço Social em relação ao trabalho $\mathrm{da}(\mathrm{o})$ assistente social exige, inicialmente, fazer referência às "Diretrizes Curriculares de 1996"1 que têm como centralidade a "questão social" e o "tra-

* DOI - 10.29388/978-65-86678-15-4-0-f.93-116

1 Cabe lembrar o conjunto de princípios que fundamenta o Currículo de 1996, a saber: Flexibilidade de organização dos currículos plenos pelas respectivas instituições de ensino; Rigoroso trato teórico, histórico e metodológico da realidade social e do Serviço Social; Adoção de uma teoria social crítica que possibilite a apreensão da totalidade social; Superação da fragmentação de conteúdos na organização curricular; Estabelecimento da dimensão investigativa e interventiva e da relação teoria e realidade como princípios formativos e condição central da formação profissional; 
balho". A “questão social” é compreendida como o conjunto da expressão de desigualdades e de lutas sociais, em suas múltiplas manifestações, constituindo o objeto ou a "matéria" sobre o qual incide o trabalho do assistente social. ${ }^{2}$

De fato, é na "questão social", mais especificamente em suas múltiplas manifestações, que o Serviço Social tem a base de sua fundação enquanto especialização do trabalho. Tais manifestações são engendradas na sociedade capitalista caracterizada por: o próprio modo de produção que lhe é específico; ${ }^{3}$ a centralidade que o trabalho assume na vida social; a produção social cada vez mais social e, em contrapartida, a manutenção da apropriação privada de seus frutos, monopolizada por uma parte da sociedade, os donos dos meios de produção; assim como, pela dinâmica da dominação abstrata que cria valor e mais valor de forma incessante. ${ }^{4}$ Nessa dinâmica a apropriação do mais-valor decorre

Padrões de desempenho e qualidade idênticos para cursos diurnos e noturnos; Caráter interdisciplinar nas várias dimensões do projeto de formação profissional; Indissociabilidade nas dimensões de ensino, pesquisa e extensão; Exercício do pluralismo através do debate sobre as várias tendências teóricas; Ética como princípio que perpassa a formação curricular; Indissociabilidade entre estágio e supervisão acadêmica e profissional.

2 A gênese e a reprodução da "questão social" são tratadas por autores reconhecidos da literatura profissional na Revista Temporalis, n 3 (2001), cuja temática é “Questão social' e Serviço Social".

3 Marx denomina "produção capitalista o modo de produção social em que o processo de produção é subsumido ao capital, ou que se baseia na relação de capital e trabalho assalariado, e isso de tal forma que ele é o modo de produção dominante, determinante" (MARX, 2010, p. 150, grifos do autor).

4 Marx, no Prefácio da $1^{a}$ Edição do Livro I de $O$ Capital, afirma que a mercadoria é a célula econômica da sociedade burguesa, é a forma que reveste o produto do trabalho. Nesta obra, Marx (1994: L.I, V.1, p. 4-5) determina como objeto de sua investigação o "modo de produção capitalista e as correspondentes relações de produção e de circulação" e trata de suas "leis naturais vigentes, tendências que operam e se impõem com férrea necessidade". Assim, inicia a crítica da sociedade moderna pela análise da mercadoria, como sua forma social estruturante mais essencial, forma histórica específica das relações que caracterizam essa sociedade, não como algo universal que existe em diferentes modos de produção, mas como forma elementar da riqueza nas sociedades onde domina o modo de produção capitalista. Isto significa que só na sociedade moderna a mercadoria "aparece" como a forma típica da riqueza: "a riqueza se configura como imenso acúmulo de mercadorias". Nesse mesmo sentido, no final dos Grundrisse, no início de uma pequena seção intitulada "Valor", Marx escreve: "A primeira categoria em que se apresenta a riqueza burguesa é a de mercadoria." (MARX, 2011, p. 756, grifos do autor). A célula econômica da sociedade burguesa é a forma mercadoria [...] Sua análise parece, ao profano, pura maquinação de minuciosidades. Trata-se, realmente, de minuciosidades, mas análogas àquelas da anatomia microscópica.” (MARX, 1994: L.I, V.1, p. 4). 
do aumento da produtividade do trabalho social expresso na grandeza crescente da massa de meios de produção em relação ao quantum de trabalho vivo necessário para acionar esses meios de produção, processo que, tendencialmente, torna a força de trabalho supérflua (ESCURRA, 2015). ${ }^{5}$

Em relação à categoria trabalho, como explicitado, considerada central nas Diretrizes Curriculares de 1996, vale lembrar que, visto que a natureza geral de produção de valores de uso não é alterada por estar sob o controle ou benefício do capitalista, Marx (1994: L.1, V.1, p. 202-209 - grifos nossos) inicia a sua exposição pela descrição do processo de produzir valores de uso em seus elementos simples e abstratos, à parte de qualquer estrutura social determinada. Nesse caso, o autor mostra que, independente de toda determinação social formal, os elementos componentes do processo de trabalho são: a atividade adequada a um fim (o trabalho), o objeto de trabalho (a matéria que é transformada pelo trabalho), os meios de trabalho (os instrumentos que fazem possível essa transformação). O trabalho é um processo em que participam homem e natureza, sendo o intercâmbio material com a natureza regulada e controlada pelo ser humano através de sua própria ação. ${ }^{6} \mathrm{Na}$ medida em que o ser humano modifica a natureza se modifica a si mesmo e desenvolve suas próprias capacidades. Trata-se aqui do trabalho como categoria fundante do ser social, trabalho dirigido com o fim de criar valores de uso, condição natural eterna da vida humana, sendo comum a todas as formas sociais. ${ }^{7}$

${ }^{5}$ Cf. Marx (1994: L.1, V.2, p. 712-752). Para uma problematização sobre o uso da lei geral da acumulação capitalista, VER Escurra (2019, p. 135-145).

${ }^{6}$ Marx ressalta, como se sabe, a capacidade que tem o ser humano de projetar previamente aquilo que depois vai produzir, o que demonstra o caráter não epifenomênico da consciência, em oposição, à estruturação existente nas chamadas sociedades animais (abelhas e formigas, por exemplo) que consiste em uma regulação biológica das ações, sem possibilidade de desenvolvimento. Por conseguinte, o trabalho realiza um pôr teleológico que dá origem a um novo produto do trabalho, uma nova objetividade, e resulta em um desenvolvimento contínuo. Cabe aqui lembrar a conhecida passagem de Marx: "o que distingue o pior arquiteto da melhor abelha é que ele figura na mente sua construção antes de transformá-la em realidade. No fim do processo do trabalho aparece um resultado que já existia antes idealmente na imaginação do trabalhador. Ele não transforma apenas o material sobre o qual opera; ele imprime ao material o projeto que tinha conscientemente em mira, o qual constitui a lei determinante do seu modo de operar e ao qual tem de subordinar sua vontade." (MARX, 1994: L.1, V.1, p. 202).

7 Uma síntese do pensamento de Lukács sobre o papel do trabalho na gênese e no desenvolvimento do ser social e, portanto, seu caráter fundante, pode ser vista no conhecido texto que o autor redigiu como base para uma conferência. Cf. Lukács (1978, p. 1-23). Para uma análise aprofundada do autor sobre a categoria trabalho como condição eterna da vida humana, portanto, não enquanto a forma que assume 
Sob essa perspectiva, Marx (2011, p. 57-61) assinala que o trabalho parece uma categoria muito simples e que sua representação como trabalho em geral, que aparenta expressar um estado de coisas presente em toda sociedade, é muito antiga. No entanto, só na mais moderna forma de existência da sociedade burguesa a categoria trabalho em geral devém verdadeira na prática e, nesse caso, o trabalho se torna meio efetivo para a criação de riqueza em geral: meio de valorização do capital e meio de subsistência do trabalhador assalariado. Além disso, observa Marx, apesar da validade das categorias mais abstratas para todas as épocas, o trabalho é produto de relações históricas e tem sua plena validade só para essas relações e no interior dessa sociedade. Ainda em relação ao trabalho, Escurra (2015) observa que Marx ao mostrar que, assim como a mercadoria, também o trabalho nela materializado possui duplo caráter, é inquestionável que se trata de uma forma de trabalho histórica específica: o trabalho que produz mercadorias. Para desenvolver seu argumento ele se concentra na relação do valor de uso do trabalho e o valor que o trabalho útil incorpora. O caráter próprio da teoria de Marx sobre o valor radica exatamente na explicação precisa do tipo de trabalho que cria valor. Ele ressalta que foi o primeiro que analisou e pôs em evidência essa natureza dupla cujo conhecimento é essencial para elaborar a crítica da economia política. ${ }^{8}$

O duplo caráter do trabalho pode ser resumido da seguinte maneira: por um lado, trabalho abstrato, dispêndio de força de trabalho no sentido fisiológico e, nessa qualidade, criador do valor das mercadorias. ${ }^{9} \mathrm{O}$ trabalho abstra-

essa categoria na sociedade capitalista, assim como tampouco sobre o papel do trabalho na constituição e na dinâmica dessa formação social particular, VER Lukács (2013, p. 41-157). Por conseguinte, o trabalho se apresenta como meio da autocriação do ser humano como ser humano: "[n]o trabalho estão contidas in nuce todas as determinações que [...] constituem a essência do novo no ser social" (LUKÁCS, 2013 , p. 44). Lukács explica que "o trabalho pode ser considerado o fenômeno originário, o modelo do ser social; parece, pois, metodologicamente vantajoso iniciar pela análise do trabalho, uma vez que o esclarecimento de suas determinações resultará num quadro bem claro dos traços essenciais do ser social. No entanto, é preciso sempre ter claro que com essa consideração isolada do trabalho aqui presumido se está efetuando uma abstração [...] O que fazemos é, pois, uma abstração sui generis; do ponto de vista metodológico há uma semelhança com as abstrações das quais falamos ao analisar o edifício conceitual de O capital de Marx". (LUKÁCS, 2013, p. 44-45).

8 Ver, especificamente, o Capítulo I de O Capital: "A Mercadoria". Sobre o duplo caráter do trabalho que produz mercadoria, consultar Escurra (2015, item 3.2).

9 Escurra (2015) ressalta a crítica de Rubin (1987, p. 147-154) à definição usual (de marxistas e críticos) de que trabalho humano é dispêndio de energia humana enquanto tal, independente de formas determinadas, pois definido dessa maneira fica 
tamente humano só existe em uma sociedade baseada na troca e expressa uma determinação puramente social do trabalho que só pode se manifestar na relação social em que uma mercadoria se troca por outra (ESCURRA, 2015). Nos termos de Marx, "[a] forma geral do valor, que torna os produtos do trabalho mera massa de trabalho humano sem diferenciações [...] é a expressão social do mundo das mercadorias" (MARX, 1994: L.I, V.1, p. 76). Desse modo, evidencia que o caráter social específico desse mundo é constituído pelo caráter humano geral do trabalho. Por outro lado, todo trabalho é dispêndio de força humana de trabalho sob forma especial, para um determinado fim e produz valores de uso, sendo nessa qualidade trabalho concreto e útil.

No interior do processo de produção capitalista, o processo de trabalho transcorre sob o controle do capitalista e o produto é sua propriedade, não do produtor direto. O capitalista compra força de trabalho e meios de produção (matérias primas, equipamentos, meios de trabalho etc.) e o processo de trabalho se converte em um processo entre coisas que lhe pertencem (ESCURRA, 2015). Nesse processo, "os meios de produção empregam o trabalhador, de tal sorte que o trabalho só aparece como um meio graças ao qual determinada quantidade de valor, ou seja, determinada massa de trabalho objetivado, suga trabalho vivo para se conservar e se incrementar." (MARX, 1985, p. 75). Contudo, como já assinalado, o valor de uso, que é resultado desse processo de trabalho, só é produzido na medida em que porta valor e mais-valor. De fato, a transformação de dinheiro em capital (e não valor de uso) é o que se objetiva com a troca de dinheiro por força de trabalho.

Após desenvolver rapidamente estas considerações gerais sobre a categoria trabalho, voltando à proposta Curricular de $1996,{ }^{10}$ é importante salientar

reduzido a um conceito fisiológico, desprovido de todos os elementos históricos e sociais. Para o autor não é possível falar em trabalho abstrato se não existir como pressuposto dispêndio de energia fisiológica por parte das pessoas, mas esse dispêndio enquanto tal não é trabalho abstrato nem cria valor. Ele conclui, então, que trabalho fisiológico e geral, ou trabalho fisiologicamente igual, não são em si trabalho abstrato, muito embora sejam seus pressupostos, visto que o valor do produto do trabalho é uma função social, e não natural, o trabalho que cria este valor não é uma substância fisiológica, mas uma substância social.

${ }^{10}$ As Diretrizes Curriculares de 1996 estão estruturadas em três núcleos articulados entre si, considerados indissociáveis, em uma relação de horizontalidade entre eles. Tais núcleos se desdobram em matérias e disciplinas, são eles: 1) Núcleo de fundamentos teórico-metodológicos da vida social que tem como objetivo a compreensão da sociedade burguesa e suas contradições; 2) Núcleo de fundamentos da formação sócio-histórica da sociedade brasileira que objetiva o conhecimento da Formação sócio-histórica do Brasil, emergência e desenvolvimento da QS, movimentos e classes subalternas; 3) Núcleo de fundamentos do trabalho 
ainda que o novo reside em entender a prática do assistente social como trabalho e seu exercicio profissional como parte de um processo de trabalho. ${ }^{11} \mathrm{O}$ marco da redefinição do projeto profissional dos anos de 1980 foi a compreensão do significado social da profissão, enquanto especialização do trabalho coletivo, inserido na divisão social e técnica do trabalho (IAMAMOTO, 1982).

A análise do exercício profissional do Serviço Social como parte de um processo de trabalho, conforme destaca Iamamoto (2008), possui suas implicações na medida em que a profissão é pensada como expressão do trabalho coletivo, sendo socialmente determinada pelas condições macro-sociais; mas, ao mesmo tempo, ela é fruto das iniciativas dos sujeitos que a realizam, os quais lhe imprimem suas finalidades éticas-políticas. Ademais, as políticas sociais se afirmam como um dos elementos constitutivos do processo de trabalho em que se insere o/a Assistente Social, enquanto uma das respostas institucionais de enfrentamento da "questão social". Em síntese, esta perspectiva destaca, fundamentalmente, a historicidade do Serviço Social, entendido no quadro das relações sociais entre as classes sociais e destas com o Estado. Significa, pois, compreender a profissão como um processo, visto que ela se transforma na medida em que se transformam as condições e as relações sociais nas quais ela se inscreve.

Cabe ressaltar que, o fato de situar este artigo na área dos fundamentos históricos e teórico-metodológicos do Serviço Social, justifica também fazer referência à produção seminal inaugurada por Iamamoto nos anos 1980, realizada em conjunto com Raul de Carvalho, especificamente a primeira parte do livro "Relações Sociais e Serviço Social". Tal produção considera o caráter contraditório do Serviço Social no âmbito do processo de produção e reprodução das relações sociais, orientando, assim, o esforço de leitura crítica da literatura especializada. Segundo essa perspectiva, o Serviço Social surge no Brasil em meados dos anos 1930, como uma especialização do trabalho coletivo inserido na divisão social e técnica do trabalho, buscando responder a demandas concretas co-

profissional que integra os conteúdos mais diretamente relacionados ao exercício profissional, à intervenção profissional. É nesse eixo que se encontra a trajetória histórica da profissão; as dimensões teórico-metodológicas, éticas-políticas, técnicooperativas; a postura investigativa; o estágio supervisionado e o TCC.

${ }^{11}$ A Proposta do Currículo Mínimo para o Curso de Serviço Social aprovada pela ABESS em 1996 foi produto de um amplo e sistemático debate realizado, a partir de 1994, pelas Unidades de Ensino, resultado da revisão do Currículo Mínimo vigente desde 1982. O Currículo Mínimo é entendido como um conjunto de diretrizes que estabelecem uma base comum, no plano nacional, para os cursos de graduação em Serviço Social, a partir da qual cada Instituição de Ensino Superior (IES) elabora seu Currículo Pleno. 
locadas tanto pelo Estado e segmentos sociais que o controlam quanto pela classe trabalhadora. ${ }^{12}$ Portanto, a profissionalização do Serviço Social pressupõe a expansão da produção e de relações sociais capitalistas, a industrialização e a urbanização, que trazem, no seu verso, a questão social que emerge com o capitalismo monopolista (NETTO, 1989).

Por último, cabe registrar que, apesar de que as Diretrizes de 1996 reconhecem o exercício profissional como trabalho, existe a perspectiva teórica que defende a tese oposta, segundo a qual o Serviço Social não é trabalho. Tal perspectiva é defendida por Lessa (2000; 2006) que, para sustentar sua posição, coloca como exemplo o trabalho assalariado de um operário industrial, de um professor e de um assistente social. A partir da comparação dos três tipos de trabalho, o autor afirma que o trabalho do operário industrial é a única atividade que cumpre a função de "intercâmbio orgânico com a natureza", produzindo o "conteúdo material da riqueza". Segundo ele, o professor e o assistente social são "complexos da esfera da reprodução", por esse motivo, são indispensáveis à realização dos atos de trabalho, mas não se confundem com ele. Trata-se, nos termos de Lessa, de "práxis preparatórias" dos atos de trabalho que possuem a ideologia como uma mediação imediata. Consequentemente, o Serviço Social seria um complexo social da esfera da reprodução responsável pela organização dos indivíduos para o trabalho. Com isso, segundo esta perspectiva, o Serviço Social não é trabalho, nem parte de um processo de trabalho, porque não efetua a transformação da natureza, mas participa de uma das mediações que organizam a sociedade de tal modo a tornar o trabalho possível. É importante registrar que, tendo como base a teoria de Marx, é possível afirmar que a leitura de Lessa que só entende como trabalho o do operário industrial, o que não condiz com o tratamento sobre o tema efetuado por Marx na sua Crítica à Economia Política, expressa em "O Capital".

${ }^{12}$ Ver Iamamoto (2008, p. 245-264), especificamente o item 3.1, intitulado "Um balanço crítico de Relações Sociais e Serviço Social no Brasil”. Nesse texto, a autora apresenta um excelente balanço da sua produção seminal, especificamente da primeira parte do livro "Relações Sociais e Serviço Social", com o objetivo de identificar os vínculos que ela conserva com o debate atual do Serviço Social brasileiro, em especial com a sua própria intervenção nesse debate. 


\section{O debate sobre processo de trabalho e sua incorpora- ção pelo Serviço Social}

Para revisitar o debate histórico crítico sobre o trabalho profissional, uma vez realizada de forma breve a referência às Diretrizes Curriculares de 1996, com ênfase na apresentação da categoria trabalho, cabe ressaltar que as condições históricas e teóricas para a discussão do processo de trabalho do assistente social como objeto de estudo são criadas a partir da interlocução do Serviço Social com a tradição marxista (ALMEIDA, 1996). Deste modo, Almeida situa na sua análise dois campos de reflexão, um primeiro diz respeito à importante contribuição de Iamamoto e Carvalho (1982) sobre a análise do significado sócio-histórico da profissão a partir das relações sociais e da divisão sociotécnica do trabalho, na sociedade capitalista, em sua fase monopolista. ${ }^{13} \mathrm{E}$ a partir desse momento, assim como da produção posterior de Iamamoto e Netto que, conforme a análise de Almeida, é inaugurada a precondição para o desenvolvimento do debate sobre o "processo de trabalho do Serviço Social", tornando possível tanto a análise da categoria dos assistentes sociais no setor de serviços, relacionada ao campo das políticas sociais públicas e privadas, assim como pensar elementos que caracterizam essa força de trabalho e o seu processo de trabalho.

Ainda em relação a esse primeiro campo de reflexão, destacada pelo autor, é relevante registrar um pressuposto importante para a análise dos espaços ocupacionais, destacado por Iamamoto (2009), de que não existe um pro-

${ }^{13}$ Cabe registrar, tal como salientado por Iamamoto (2008, p. 254) que colocar o foco no significado social da profissão na sociedade capitalista elimina "o padrão endógeno, então predominante nas interpretações da profissão. Indaga sobre a sua necessidade social, seus efeitos na sociedade e as mediações sociais por meio das quais se realiza. Em outros termos, procura identificar as particularidades dessa especialização do trabalho, abordando-a nas suas dimensões de trabalho concreto e trabalho abstrato." (este aspecto é desenvolvido no item 4 deste texto). Ainda em relação ao padrão endógeno, é oportuno recuperar o pressuposto da mesma autora que mostra que é necessário romper com essa visão endógena, focalista, visão de dentro do Serviço Social, sendo preciso, desse modo, extrapolar o Serviço Social para sua melhor apreensão na história da sociedade da qual ele é parte e expressão (IAMAMOTO, 1998). Com isso, o desafio é situar o Serviço Social na história ao invés de tratar a sua história reduzida aos muros da profissão. Um claro exemplo de uma visão de dentro e por dentro das fronteiras do Serviço Social é a frequente afirmativa de que ele se torna profissão quando se processa uma tecnificação da filantropia, como se fosse fruto de uma evolução interna e autônoma dos sujeitos que a ele se dedicam (IAMAMOTO, 2004). 
cesso de trabalho do Serviço Social. Existe sim um trabalho do/a assistente social e processos de trabalho nos quais esse profissional se envolve na condição de trabalhador(a) especializado(a). Em outras palavras, contra o mito de um único processo de trabalho, existem diferentes processos de trabalho nos quais se inscreve a atividade do(a) assistente social. Por conseguinte, segundo a autora, considerar o exercício profissional como processo de trabalho subentende compreender a profissão como parte do trabalho coletivo, determinada socialmente pelas condições macro-sociais e pelas iniciativas dos sujeitos que a realizam na medida em que imprimem à profissão suas finalidades ético-políticas. Ademais, as políticas sociais se afirmam como um dos elementos constitutivos do processo de trabalho do assistente social, enquanto uma das respostas institucionais para o enfrentamento da "questão social".

O segundo campo de reflexão assinalado por Almeida oferece uma rica problematização acerca das políticas sociais e da assistência, terreno em que se gesta essa prática profissional. Trata-se da contribuição de Faleiros sobre políticas sociais no Estado capitalista e da produção da PUC-SP sobre políticas sociais de assistência, na trajetória das políticas sociais no Brasil. A estas se agregam as contribuições de Behring (2003;2007), Boschetti (2003), Mota (1995), dentre outras.

Por outro lado, cabe registrar, ainda, a iniciativa pioneira da Faculdade de Serviço Social da Universidade do Estado do Rio de Janeiro - UERJ, visto que inaugura a temática do processo de trabalho no âmbito da formação profissional, incorporando-a ao seu próprio currículo de graduação (ALMEIDA, 1996). Barbosa, Almeida e Cardoso (1998) observam que o pensamento social tem vinculado processo de trabalho à esfera fabril ou, quanto muito, ao setor bancário na área de serviços. Desse modo, os autores apresentam a hipótese de que é possível recuperar o conceito de "processo de trabalho" e tomá-lo como referência para a compreensão do trabalho do assistente social. Em outras palavras, a categoria "processo de trabalho" contribuiria para a compreensão dos principais fenômenos do trabalho de assistentes sociais. Nesse contexto, os autores sustentam algumas peculiaridades deste trabalho, a saber: o Serviço Social é uma profissão, um trabalho especializado que exige diplomação superior, possui mandato legal e científico, assim como autonomia técnica; o trabalho do assistente social se realiza na tensão entre uma autonomia técnica e a lógica estrutural do trabalho capitalista; a autonomia legal é confrontada com a própria condição de assalariamento com que o profissional de serviço social sempre exerceu seu trabalho, pois ao vender sua força de trabalho ele é submetido às normas institucionais; no seu trabalho revela-se uma característica que está pre- 
sente dentro de atividades da esfera dos serviços, na medida em que está voltado para a produção de condições necessárias à manutenção do processo social de produção.

Como síntese do exposto, pode-se destacar que o Serviço Social se materializa no âmbito de um processo de trabalho, inserido em um processo coletivo, a partir dos seguintes aspectos: possui as manifestações da "questão social" como objeto de ação profissional; conta com instrumentos de intervenção firmados nas bases teórico-metodológicas, apreendidas enquanto profissão regulamentada, que se materializam em entrevistas sociais, reuniões, encaminhamentos, pareceres sociais etc.; os "produtos", ou os resultados desse trabalho, podem contribuir ou não para a construção de outra sociedade onde seja superada a contradição capital e trabalho que potencializa a "questão social"; por estar inserido em um processo coletivo de trabalho o Serviço Social não atua de forma isolada de outros profissionais, podendo estabelecer alianças e desenvolver estratégias conjuntas para o enfrentamento da "questão social".

Ainda em relação ao tema, outra questão a ser destacada é a tensão que existe entre o projeto ético-político profissional e o estatuto assalariado. Tal tensão é analisada por Iamamoto $(2008 ; 2009)$ ao ressaltar que nas suas ações profissionais a autonomia relativa $\mathrm{da}(\mathrm{o})$ assistente social encontra-se legitimada socialmente pela formação acadêmica universitária, pelo aparato legal e organizativo que regula o exercício de uma profissão liberal e pelas lutas da categoria. A autora também chama a atenção para o fato de que a mercantilização da força de trabalho, pressuposto do estatuto assalariado, subordina o trabalho do assistente social aos dilemas do trabalho abstrato e o impregna dos dilemas da alienação, impondo, desse modo, condicionantes objetivos à sua autonomia na condução do seu trabalho e à integral implementação do Projeto Profissional. ${ }^{14}$

No contexto das transformações e redefinições do trabalho nos dias atuais, Raichelis problematiza alguns aspectos do processo de precarização que caracteriza o mundo do trabalho, afirmando que "os efeitos da tríade flexibiliza-

${ }^{14}$ O Projeto Profissional do Serviço Social expressa uma condensação das dimensões ético-políticas, teórico-metodológicas e técnico-operativas e engloba a formação e o exercício profissional. Conforme Teixeira e Braz (2009), o Projeto Profissional do Serviço Social se materializa a partir do seguinte tripé: a produção de conhecimento no interior da profissão na perspectiva da teoria social crítica; as suas instâncias político-organizativas que pressupõem um espaço democrático de construção coletiva (conjunto CFESS/CRESS, ABEPSS, ENESSO); a dimensão jurídico-política da profissão que envolve o atual Código de Ética da profissão, a Lei de Regulamentação da Profissão (Lei 8662/93), as Novas Diretrizes Curriculares e leis que, se bem não são exclusivas da profissão, são implementadas pelos assistentes sociais (exemplo: Estatuto da Criança e do Adolescente etc.). 
ção/precarização/terceirização do trabalho do assistente social se fazem sentir em níveis e intensidade antes desconhecidos pela profissão" (RAICHELIS, 2011, p. 431). Diante disso, no contexto de intensificação e precarização do trabalho, a autora assinala a passagem "da autonomia relativa à autonomia controlada" do trabalho do(a) assistente social, chamando a atenção para o crescimento de demandas institucionais dirigidas que provocam redefinições no âmbito do Estado e nas políticas sociais, desencadeando, assim, novas solicitações, exigências e possibilidades ao trabalho profissional. Além disso, observa Raichelis (2011), a relação dos assistentes sociais junto aos usuários e à população passa a ser mediada pelo "computador" como efeito da revolução tecnológica na sua atuação, fragilizando o trabalho direto com segmentos populares em processos socioeducativos, de mobilização e organização em uma perspectiva emancipatória.

\section{Literatura profissional, a legitimação do trabalho do assistente social enquanto trabalho concreto e o desafio de sua inserção no universo do valor}

Para um balanço do debate sobre o processo de trabalho e de sua incorporação pelo Serviço Social, o capítulo III do livro "Serviço Social em tempo de capital fetiche" de Iamamoto (2008) traz elementos para um diálogo crítico onde estabelece uma interlocução com parcela da literatura profissional brasileira, inscrita na teoria social crítica sob diversas inspirações (Hegel, Marx, Gramsci, Lukács). Tal interlocução tem como objetivos identificar os diferentes ângulos de análise dos autores em relação ao trabalho do assistente social na divisão social e técnica do trabalho e apontar silêncios e omissões que possam orientar a agenda da pesquisa na área do trabalho profissional.

A hipótese de Iamamoto é que a análise da profissão na divisão social e técnica do trabalho foi largamente incorporada pela categoria profissional. De fato, a literatura centrou-se predominantemente nas particularidades do Serviço Social, enquanto trabalho concreto segundo focos distintos: as origens da profissão na expansão monopolista e o sincretismo (NETTO, 1991; 1992; 1996); a identidade e a alienação (MARTINELLI, 1989); as políticas sociais, as relações de força, poder e exploração (FALEIROS, 1987; 1999); a proteção e a assistência social (COSTA, 2000), (YAZBEK, 1993; 1998); a hegemonia e a organização da cultura (SIMIONATTOO, 1995), (ABREU, 2002). 
Diante disso, Iamamoto alerta sobre o risco de restringir a abordagem do processo de trabalho à óptica do valor de uso (ao trabalho útil, concreto) desvinculando-o de suas implicaçoes na órbita do valor (do trabalho humano abstrato). ${ }^{15}$ Por conseguinte, ela observa que no período compreendido entre os anos de 1980-2000, o tratamento do trabalho do(a) assistente social tinha como ponto principal o seu caráter de trabalho útil, concreto, de uma qualidade determinada, que satisfaz necessidades sociais. Entretanto, sua análise deixa evidente que o desafio é incorporar e ir além dessa perspectiva, visto que a satisfação de necessidades sociais exige a troca de determinado trabalho concreto, sendo preciso, desse modo, sua troca por qualquer outro tipo de trabalho privado útil, o que exige a abstração de sua particularidade e a identificação de algo comum entre eles. Nas suas palavras,

Impõe incorporar na análise a outra dimensão desse trabalho especializado e dele indissociável: o fato de ser trabalho social médio, isto é, trabalho abstrato, considerando, portanto, sua inserção no universo do valor. É nesse universo que se estabelece o valor de troca dessa força de trabalho especializada - o salário do assistente social- parte do trabalho social médio, pensado na sua quantidade, medido pelo tempo de trabalho socialmente necessário. Lembrese que a força só tem valor de uso para seu possuidor quando é valor de troca, isto é, quando é passível de ser trocada por dinheiro para satisfação de suas necessidades. (IAMAMOTO, 2008, p. 257).

A autora mostra, desse modo, que a literatura profissional que tem o Serviço Social como objeto de estudo centra-se na qualidade desse trabalho, em sua dimensão de trabalho concreto, em seu valor de uso social. Entretanto, ela chama a atenção, ao fato de que nessa mesma literatura o que não dispõe de centralidade é o mesmo trabalho do assistente social enquanto trabalho abstrato, visto que não trata as implicações do trabalho do assistente social no circuito do valor - da produção e distribuição do valor e do mais-valor. Neste senti-

${ }^{15}$ Em relação à sua pesquisa atual Iamamoto afirma um aspecto fundamental que, na realidade, fica evidente na leitura da sua produção dado que: "volta-se ao processo de realização do projeto profissional, em suas dimensões técnicas, políticas e éticas, nas condições sociais em que opera o trabalho do assistente social e as formas por ele assumidas no âmbito das específicas relações sociais em que se inscreve no Estado, nas organizações empresariais, em entidades da sociedade civil e congêneres. Essa síntese de minhas preocupações atuais é suficiente para atribuir transparência aos elos de continuidade com o debate de 1982 e seus desdobramentos históricos e analíticos" (IAMAMOTO, 2008, p. 255). 
do, cabe registrar que Iamamoto já nos anos de 1980, em "caráter preliminar", afirma que

[...] o Serviço Social não é uma profissão que se inscreva, predominantemente, entre as atividades diretamente vinculadas aos processos de criação de produtos e valor, o que não significa o seu alijamento da produção em sentido amplo (produção, distribuição, troca e consumo). Sendo o alvo do exercício profissional o trabalhador e sua família, o Serviço Social, ao inscrever-se no contexto referente às condições e situação de vida da classe trabalhadora, encontra-se integrado ao processo de criação das condições indispensáveis ao funcionamento da força de trabalho, à extração da mais-valia. (IAMAMOTO, 2008, p. 256).

É oportuno lembrar que no processo de trabalho, a força de trabalho e os meios de produção desempenham papéis bem diferentes no valor das novas mercadorias produzidas. No processo capitalista de trabalho o trabalhador tem de produzir o valor de sua força de trabalho, além do mais-valor. ${ }^{16}$ A conversão da soma de valores adiantada sob a forma de dinheiro ou mercadorias em capital, por conseguinte, é resultado da transformação do capital variável em força de trabalho (ESCURRA, 2015). Com isso, destaca Marx (1994: L. 1, V.1, p. 235), as mesmas partes do capital que do ponto de vista do processo de trabalho se distinguem em elementos objetivos (meios de produção) e elementos subjetivos (força de trabalho), se diferenciam, do ponto de vista de produzir mais-valor, em capital constante e capital variável. Como dito, o mais-valor é simples decorrência da variação de valor que ocorre na parte variável do capital - parte do capital aplicada em força de trabalho. Entretanto, pelo fato de que com o crescimento da parte variável do capital ocorre simultaneamente o au-

16 Os meios de produção consumidos na produção da mercadoria não criam valor, mas transferem seu valor de forma parcial ou integral ao valor da mercadoria, segundo se trate de equipamentos, instrumentos, matérias primas, energia etc. Explica-se assim, porque Marx (1994: L.1, V.1, p. 224-236) denomina "capital constante" a parte do capital que se converte em meios de produção, cuja magnitude de seu valor não se altera no processo de produção. Inversamente, a parte do capital convertida em força de trabalho que muda de valor no processo de produção é denominada de parte variável do capital ou "capital variável". Essa parte do capital reproduz o próprio equivalente, quantidade de trabalho igual ao valor do capital variável ou do salário e proporciona um mais-valor, um quantum adicional de trabalho, um excedente que varia, podendo ser menor ou maior. Em outras palavras, "a capacidade viva de trabalho, que gera valor, um elemento que produz valores [...] só entra no processo produtivo como seu fator apenas como grandeza fluida, em devir, [...] não como grandeza havida, fixada" (MARX, 1985, p. 49). 
mento do capital global desembolsado é obscurecida a verdadeira variação de valor e a proporção em que o valor se altera. ${ }^{17}$

Neste contexto, é importante reforçar, mais uma vez, que o processo de produção capitalista possui um caráter duplo semelhante ao trabalho que produz mercadorias - trabalho concreto que produz valores de uso e trabalho abstrato que cria valor. No caso do processo de produção capitalista, tal caráter duplo se apresenta enquanto unidade de processo de trabalho (que produz determinado valor de uso) e processo de valorização (que gera valor e mais-valor). "Trata-se de valorizar o valor. Portanto, não somente de um processo de trabalho, mas de um processo de valorização.” (MARX, 2010, p. 81).

O processo de produção como unidade de processo de trabalho e de processo de valorização torna evidente que se trata apenas de um único processo de trabalho, indissociável, pois não se trabalha duas vezes, uma para criar um valor de uso e outra para valorizar o valor, criar valor e mais-valor (MARX, 1985, p. 57). Portanto, o processo de trabalho sob a ótica do capital só se apresenta como meio e o processo de valorização como fim: “[o] produto do processo de produção capitalista não é nem o mero produto (valor de uso), nem uma mera mercadoria, quer dizer, um produto que tem valor de troca; o seu produto específico é o mais-valor" (Ibid., p. 68, grifos do autor).

Com isso, a especificidade da forma capitalista de produzir mercadorias é enunciada da seguinte forma:

[...] o processo de produção, quando unidade do processo de trabalho e do processo de produzir valor, é processo de produção de mercadorias; quando unidade do processo de trabalho e do processo de produzir mais-valor, é processo capitalista de produção, forma capitalista da produção de mercadorias (MARX, 1994: L.1, V.1, p. 222). ${ }^{18}$

${ }^{17} \mathrm{O}$ consumo da força de trabalho se realiza fora da esfera da circulação. Assim Marx revela que, para ver como o capital produz e é produzido, é preciso acompanhá-los (o dono do dinheiro e o possuidor da força de trabalho) ao "local reservado da produção", abandonando essa "esfera ruidosa [da circulação], onde tudo ocorre na superfície e à vista de todos". "Veremos aí [na esfera da produção] como o capital produz e, também, é produzido. O mistério da criação do valor excedente (maisvalor) se desfará finalmente." (MARX, 1994: L.1, V.1, p. 196). Na medida em que o mais-valor é valor para além do equivalente, tem de brotar do próprio processo de produção do capital; ele jamais pode brotar do equivalente, por isso, tampouco pode surgir da circulação (MARX, 2011, p. 255).

${ }^{18}$ Neste sentido, Marx (1985, p. 57, grifos do autor) explicita que o caráter global do processo de produção capitalista se encontra especificamente determinado da seguinte maneira: “[o] processo de produção é a unidade imediata do processo de 
O que diferencia o processo de produzir mais-valor em relação ao processo de produzir valor é o fato de prolongar a produção de valor além de certo ponto: a duração até o ponto em que o valor da força de trabalho pago pelo capital é substituído por um equivalente é o processo de produzir valor; excedendo esse ponto, o processo de produzir valor torna-se processo de produzir mais-valor (MARX, 2010, p. 220). ${ }^{19}$ É oportuno registrar que o aumento ilimitado do mais-valor não é resultado da vontade ou de problemas morais dos capitalistas individuais, mas um imperativo da própria lógica da produção capitalista, das leis inerentes do capital que se impõem frente a eles como leis coercitivas da concorrência (ESCURRA, 2015). ${ }^{20}$ Portanto, a necessidade de mais trabalho é uma das implicações da forma de trabalho imposta pela lógica do valor.

Nesta perspectiva, Iamamoto (2008) fundamenta sua análise sobre o trabalho do(da) assistente social e alerta para a necessidade de incorporar não só sua abordagem enquanto trabalho concreto, útil, de uma qualidade determi-

trabalho e do processo de valorização, assim como o seu resultado, o resultado imediato, a mercadoria, é unidade imediata do valor de uso e do valor de troca. Mas o processo de trabalho não é mais do que um meio do processo de valorização, processo que, por sua vez, enquanto tal, é essencialmente producão de mais-valor, isto é, processo de objetivação de trabalho não pago."

${ }^{19}$ Marx (1985, p. 124) denomina "mistificação do capital" o processo de produção em que todas as forças produtivas sociais do trabalho se apresentam como propriedades intrínsecas do capital, como forças produtivas do capital. Com isto, "[a] transposição das forças produtivas sociais do trabalho em propriedades objetivas do capital, ganhou a tal ponto terreno na imaginação que as vantagens da maquinaria, da aplicação da ciência, etc., se concebem nesta forma alienada como forma necessária e portanto tudo isto como propriedades do capital." (Ibid., 131, grifos do autor). Em consequência, Marx conclui que a riqueza criada pelo trabalhador como capital se converte em uma força do capital e, ao mesmo tempo, o desenvolvimento da produtividade do trabalho social se transforma em desenvolvimento das forças produtivas do capital (MARX, 2010, p. 127). Nesta mesma perspectiva, Heinrich (2008, p. 122) chama "fetichismo do capital" à aparência de que o capital é um poder dotado de força produtiva própria e que possui, ao igual que o fetichismo da mercadoria, seu fundamento material na organização capitalista do processo de produção.

${ }^{20} \mathrm{O}$ fato de que para Marx as pessoas representam categorias econômicas fica patente na passagem em que escreve: "[n]ão foi róseo o colorido que dei às figuras do capitalista e do proprietário de terras. Mas, aqui, as pessoas só interessam na medida em que representam categorias econômicas, em que simbolizam relações de classe e interesses de classe. Minha concepção do desenvolvimento da formação econômicosocial como um processo histórico natural exclui, mais do que qualquer outra, a responsabilidade do indivíduo por relações, das quais ele continua sendo, socialmente, criatura, por mais que, subjetivamente, se julgue acima delas." (MARX, 1994: L. 1, V.1, p. 6). 
nada, que satisfaz necessidades sociais, mas, também, a importância de identificar o fato de ser dispêndio de força humana de trabalho, em outras palavras, trabalho social indistinto, valor. Diante disso, cabe lembrar ainda, o debate aberto em 1982 sobre o Serviço Social como trabalho produtivo e/ou improdutivo.

O Serviço Social - profissional situado na "linha de frente" no âmbito da prestação de serviços entre o Estado e/ou empresário capitalista e os cidadãos que a eles tem direito - qualificado como "executor terminal das políticas sociais" (NET"TO, 1989, p. 71-72) - tem no Estado seu maior empregador nesse âmbito, dada a exigência de administrar uma série de atividades que, apesar de não serem produtivas, são necessárias ao movimento do capital e para a produção e reprodução capitalista. Trata-se, nos termos de Iamamoto (1982), de atividades vinculadas de forma direta ao "poder político-ideológico e / ou repressivo do Estado", no contexto da modernização do seu aparato burocrático, dada a necessidade de assegurar o domínio de classe. Fica evidente, portanto, o significado do Serviço Social na reprodução das relações sociais, em particular, na "reprodução do controle e da ideologia dominante" (IAMAMOTO, 2008).

A autora alerta que esses serviços sociais precisam ser compreendidos na "órbita do valor", uma metamorfose de mais-valor, atualmente denominado de "fundo público". Portanto, a partir do fato de que toda riqueza existente é fruto do trabalho humano, ela é distribuída na forma de rendimentos diferentes para o capital (lucro industrial, comercial e juros), os proprietários fundiários (renda da terra) e os trabalhadores (salário). Desse modo,

[...] parte da riqueza social é transferida ao Estado, especialmente sob a forma de impostos e taxas pagos por toda a população, parte do valor criado pela classe trabalhadora é apropriado pelo Estado e pelos segmentos dominantes e redistribuído sob a forma de serviços sociais. [...] Nesse quadro, os serviços sociais assumem a aparência de 'doação' de parte do poder político ou do capital, dotados de uma máscara humanitária. (IAMAMOTO, 2008, p. 261-262)

Diante o exposto, é importante fazer, ainda, uma breve referência à diferenciação de trabalho produtivo e improdutivo feita por Marx. ${ }^{21}$ Conforme já assinalado, na análise marxiana fica explícito que, na medida em que o trabalhador não produz para si, mas para o capital, é preciso que, além de produzir, crie mais-valor visto que a produção capitalista é necessariamente produção de valor e de mais-valor. A diferenciação entre trabalho produtivo e trabalho improduti-

${ }^{21}$ Estas considerações foram extraídas de Escurra (2015). 
vo feita por Marx diz respeito à acumulação, dado que toda a dinâmica do capitalismo depende do mais-valor produzido, e quem o produz é o trabalhador produtivo; ou seja, a massa de mais-valor e sua reconversão em capital depende do trabalho produtivo. Sob este ângulo, só é produtivo o trabalhador que serve à autoexpansão do capital: que produz mais-valor para o capitalista (MARX, 1994: L.1, V.2, p. 584). Com isto, o conceito de trabalhador produtivo, assinala Marx, compreende uma relação de produção específica, histórica, em que o instrumento direto de criar mais-valor é o trabalhador. "A determinação do trabalho produtivo (e, por conseguinte também a do improdutivo, como seu contrário) baseia-se, pois no fato de a produção do capital ser produção de mais-valor e de o trabalho por ela empregado ser trabalho produtor de mais-valor." (MARX, 1985, p. 120, grifos do autor).

Para esclarecer tal conceito, Marx apresenta o caso do mestre-escola, um exemplo fora da esfera da produção material, evidenciando que este trabalhador é produtivo "quando trabalha não só para desenvolver a mente das crianças, mas também para enriquecer o dono da escola. Que este inverta seu capital numa fábrica de ensinar, em vez de numa de fazer salsicha, em nada modifica a situação.” (MARX, 1994: L.1, V.2, p. 584). Ele ilustra a mesma questão trazendo além do caso do mestre-escola, o de uma cantora que é trabalhadora improdutiva, mas que é produtiva no caso de ser contratada por um empresário para valorizar o seu dinheiro, pois, aqui a cantora produz diretamente capital (MARX, 1985, p. 115)..$^{22}$ Ser trabalhador produtivo ou não, portanto, importa do ponto de vista do capital, do proprietário de dinheiro e não do ponto de vista do trabalhador.

${ }^{22}$ Marx (2011, p. 212) deixa claro que no caso de todas as prestações de serviço que são consumidas por pessoas que trocam diretamente o serviço de trabalhadores pelo seu dinheiro é consumo de renda que pertence à circulação simples, não à circulação do capital, não podendo tal prestação de serviço entrar na categoria de trabalho produtivo, pois não existe a contraposição de um dos contratantes em relação ao outro como capitalista. No caso de um capitalista que manda cortar lenha para assar seu carneiro, exemplifica o autor, lenhador e capitalista se encontram na relação de troca simples: o lenhador lhe dá ao capitalista seu serviço, um valor de uso que não aumenta seu capital; e o capitalista em troca lhe dá outra mercadoria sob a forma de dinheiro. Nesse caso, quem fornece o dinheiro e quem proporciona o serviço representam um perante o outro os dois lados da circulação simples, estando interessados no valor de uso do serviço e no dinheiro de quem compra a mercadoria, respectivamente. Assim concebido o trabalho improdutivo envolve uma infinidade de atividades das quais Marx ironicamente comenta: "[d]a puta ao papa, há uma multidão dessa ralé. Mas também faz parte dela o lumpem proletariado honesto e 'trabalhador'; p. ex., grandes bandos de serviçais etc. que prestam serviço nas cidades portuárias etc.” (MARX, 2011, p. 212). 
Com o desenvolvimento da subordinação real do trabalho ao capital uma força de trabalho socialmente combinada se converte em agente - e não o trabalhador individual -, incorporando como consequência no conceito de trabalho produtivo um número cada vez maior de funções de força de trabalho diretamente subordinadas ao processo de produção e de valorização do capital. Com isso, para evitar o erro que restringe o conceito de trabalho produtivo ao trabalhador manual, é importante frisar que: "[...] é absolutamente indiferente que a função deste ou daquele trabalhador, mero elo deste trabalhador coletivo, esteja mais próxima ou mais distante do trabalho manual direto" (MARX, 1985, p. 110).

Ainda em relação à definição de trabalho produtivo, Rubin (1987, p. 283) sublinha que do ponto de vista da definição marxiana não é possível relacionar o trabalho do servidor público, da polícia, dos soldados e sacerdotes a essa definição, mas não pelo fato de serem trabalhos inúteis ou porque não se materializem em coisas, senão porque estão organizados sobre princípios de direito público e não sobre princípios capitalistas. ${ }^{23}$ Entretanto, esclarece o autor, se a proteção de cargas e passageiros nas estradas não é realizada pela polícia estatal, mas por agências privadas de transportes através de trabalhadores empregados, os membros dessas agências sujeitas às leis da produção capitalista são trabalhadores produtivos. $^{24}$

A partir das considerações até aqui apresentadas, já é possível afirmar que o que constitui o caráter específico do trabalho produtivo para o capital é o seu caráter de fator criador de mais-valor, e não o seu caráter útil determinado, nem as qualidades úteis particulares do valor de uso em que se objetiva o trabalho, motivo pelo qual um trabalho de idêntico conteúdo pode ser tanto produtivo como improdutivo (MARX, 1985, p. 115). Portanto, "somente é produtivo o trabalho que produz capital $[\ldots]$ o trabalho que não o faz, por mais útil que

23 "E possível que eles mesmos sejam algumas das condições para se fazer dinheiro, como policiais, juízes, soldados, carrascos. Porém, elas o são sempre somente como 'circunstância agravante' e nada têm que ver com o processo direto" (MARX, 2010, p. 151).

${ }^{24}$ Nesta perspectiva, Rubin (1987, p. 288-290) explica que o trabalho do vendedor, que é empregado pelo capital na fase de circulação, não é produtivo não por não produzir modificações nos bens materiais, pois um palhaço empregado por um empresário circense (assim como a cantora mencionada por Marx) é um trabalhador produtivo, apesar de não provocar modificações em bens materiais. O autor ressalta, inclusive, que "as concepções dos autores que reduzem a teoria do trabalho produtivo de Marx a uma diferença entre trabalho incorporado em coisas materiais e o que não possui esta propriedade, devem ser reconhecidas como incondicionalmente errôneas" (RUBIN, 1987, p. 292-293). 
possa ser - pode muito bem ser nocivo -, não é produtivo para a capitalização, logo é trabalho improdutivo" (MARX, 2011, p. 238, grifos do autor). ${ }^{25}$

Outro aspecto que merece ser destacado é a tendência do capital de absorver todos os ramos de produção, submetendo-os à sua lógica, como é exemplo da indústria da comunicação (seja de transporte de pessoas e de mercadorias, transmissão de informações, envio de cartas telegramas, comunicação virtual), e também o caso da industrialização dos serviços, em que o produto do processo de produção não é uma mercadoria com existência autônoma (IAMAMOTO, 2008, p. 84). Essas ilustrações são importantes para desmistificar tanto o equívoco de que o trabalho produtivo só se expressa em coisas materiais e quando se opera uma transformação imediata da natureza, como para mostrar que ao longo do século XX o capitalismo, para estender a esfera da valorização, mercantilizou setores cada vez mais amplos e diversificados da vida. Em síntese, é importante frisar que para a definição de trabalho produtivo Marx aborda o trabalho exclusivamente do ponto de vista de sua forma social. Tal definição não depende do caráter, conteúdo, resultado concreto, útil do trabalho, nem se o produto do trabalho resulta de um trabalho físico ou intelectual, sendo indiferente também se o trabalho serve para a satisfação de necessidades materiais ou espirituais. Em consequência, somente é trabalho produtivo o trabalho organizado sob princípios capitalistas, que se troca diretamente por dinheiro enquanto capital, dinheiro que como capital se contrapõe à força de trabalho tendo em vista à sua valorização. Isto significa que é só na órbita da produção - portanto do capital na sua forma produtiva - que há produção de valor e de mais-valor: só aí se realiza trabalho produtivo. ${ }^{26}$

${ }^{25}$ Nos termos de Iamamoto, “o critério determinante que afirma o caráter de trabalho produtivo não é o conteúdo do trabalho ou sua qualidade determinada enquanto trabalho útil, mas sim sua forma de organização compatível com a produção capitalista [...] O critério é a forma social determinada assumida pelo trabalho ou as relações de produção sob as quais se realiza. Daí que o mesmo trabalho pode ser produtivo ou não, caso esteja ou não organizado sob a forma capitalista. Como já sustentou Marx, o trabalho improdutivo é aquele que se troca diretamente por renda, isto é, salário e lucro, incluindo, as categorias que participam, como sócios, do lucro do capitalista industrial, absorvendo, sob as formas de lucro comercial, juros e renda fundiária, parte do mais-valor social produzido." (IAMAMOTO, 2008, p. 83, grifos da autora).

26 “Ademais, para o trabalho ser produtivo no sentido capitalista é necessário que seja trabalho assalariado, não obstante, nem todo trabalhador assalariado é produtivo, visto ser possível adquirir trabalho a ser consumido como valor de uso, como serviço e não incorporado no processo capitalista de produção. Aqui o trabalho é consumido improdutivamente, pois é consumido por seu valor de uso, não como trabalho que gera valores de troca. Por esse motivo, como já mencionado, quem consome esse 


\section{Considerações finais}

Longe da pretensão de dar por esgotada a reflexão, o conjunto de aspectos tratados neste texto teve o propósito de fundamentar a relevância e a pertinência da categoria "trabalho" com base na Crítica da Economia Política de Marx para a análise do trabalho do assistente social. O caminho proposto situa tal análise na área de fundamentos históricos e teórico-metodológicos do Serviço Social e propõe recuperar a leitura de Iamamoto em "Serviço Social em Tempo de Capital Fetiche", afirmando, mais uma vez, a necessidade de abordar o trabalho profissional com base no duplo caráter que o trabalho assume sob o capital.

No contexto de avanço da cultura neoconservadora que se caracteriza por um retrocesso assustador manifesto nas diferentes dimensões da vida social é evidente a degradação de direitos e de conquistas históricas acumuladas na sociedade brasileira, tanto pela classe trabalhadora, quanto pelo Serviço Social. Com isso, talvez seja interessante apresentar uma síntese de desafios do Serviço Social assinalados por Iamamoto $(1995 ; 2008)$ que, sem dúvida se renovam e ganham atualidade, a saber: romper com uma visão endógena, focalista, uma visão "de dentro" do Serviço Social, como condição para requalificar o fazer profissional e descobrir alternativas de ação; integrar a análise da profissão na realidade social, desenvolver a capacidade de decifrar a realidade e construir propostas criativas, ser um profissional "propositivo" e não só "executivo"; analisar o trabalho do assistente social de forma indissociável dos dilemas vividos pelo conjunto dos trabalhadores e suas lutas; romper com as unilateralidades presentes nas leituras "fatalistas" e "messiânicas" do trabalho do assistente social; superar as abordagens unilaterais, dado que as dimensões teórico-metodológica, ético-político e técnico-operativo são fundamentais e complementares; afirmar a pesquisa como uma dimensão integrante do exercício profissional; exigir uma rigorosa formação teórico-metodológica que permita compreender o processo de desenvolvimento capitalista, a particularidade brasileira e as refrações nas políticas públicas e no exercício profissional; garantir a qualidade acadêmica da formação universitária ante a expansão do ensino superior privado e da graduação a distância no país; tornar o projeto ético-político um guia efetivo para a prática e consolidá-lo por meio de sua implementação; manter viva, tanto a crítica ao conservadorismo profissional, quanto à vulgarização marxista, no res-

valor de uso troca o seu dinheiro como renda que funciona como meio de circulação e não como capital." (ESCURRA, 2015, p. 143). 
gate do legado marxiano para inspirar a análise da sociedade da profissão. Finalmente, como já sabido, cabe registrar que o Serviço Social brasileiro se redimensionou, se renovou e exerce um papel de vanguarda no cenário internacional. Assim, o grande desafio é salvaguardar as conquistas do projeto profissional no Brasil e dar continuidade ao processo de articulação do Serviço Social brasileiro com o Serviço Social latino-americano e com países de outros continentes, através de vínculos de entidades representativas de níveis de formação, de exercício profissional e do movimento estudantil, de redes de pesquisa, cooperação técnica e de intercâmbio acadêmico-profissional.

\section{Referências}

ABESS/CEDEPSS. Diretrizes Gerais para o Curso de Serviço Social (Com base no currículo mínimo aprovado em Assembleia Geral Extraordinária de 08 de novembro de 1996). Formação Profissional: Trajetória e Desafios. Cadernos ABESS. São Paulo, n. 7, Edição Especial, p. 58-76, nov. 1997a.

. Proposta básica para o projeto de formação profissional: novos subsídios para o debate. Cadernos ABESS. São Paulo, n. 7, p. 15-58, nov. 1997b. ABREU, M.M. Serviço Social e organização da cultura: perfis pedagógicos da prática profissional. São Paulo: Cortez, 2002.

ALMEIDA, N.L.T. de. Considerações para o exame do processo de trabalho do Serviço Social. Serviço Social e Sociedade. São Paulo, n. 52, Ano XVII, p. 2447, dez. 1996.

BARBOSA, R.N.C; ALMEIDA, N. L. T. de; CARDOSO, F. G. A categoria "processo de trabalho" e o trabalho do assistente social. Serviço Social e Sociedade. São Paulo, n. 58, Ano XIX p. 109-130, nov. 1998.

BEHRING, E. R. Brasil em contra-reforma: desestruturação do Estado e perda de direitos. São Paulo: Cortez, 2003.

Política Social no capitalismo tardio. 3. ed. São Paulo: Cortez, 2007.

BOSCHETTI, I. Assistência Social no Brasil: um direito entre originalidade e conservadorismo. 2. ed. ver. aum. Brasília, 2003

COSTA, D. H. O trabalho nos serviços de saúde e a inserção do assistente social. Serviço Social e Sociedade. São Paulo, n. 62, p. 35-72, mar. 2000. 
ESCURRA, M. F. Pobreza no capitalismo: elementos para a análise crítica com base na teoria valor-trabalho de Marx. Orientadora: Marilda Villela Iamamoto. 2015. Tese (Doutorado em Serviço Social - Programa de Pós-Graduação em Serviço Social, UERJ, 2015, original inédito.

- Marx e a pobreza ou a influência do aumento do capital para a classe trabalhadora. Textos \& Contextos. Porto Alegre, v. 18, n. 1, p. 135-145, jan./ jun. 2019.

FALEIROS, V. P. Saber profissional e poder institucional. São Paulo: Cortez, 1987.

. Estratégias em Serviço Social. 2. ed. São Paulo: Cortez 1999.

HEINRICH, M. Crítica de la economía política: una introducción a El Capital de Marx. Madrid: Escolar y Mayo Editores, 2008.

IAMAMOTO, M. V. Renovação e conservadorismo no Serviço Social: ensaios críticos. 3. ed. São Paulo: Cortez, 1995.

. O Serviço Social na contemporaneidade: trabalho e formação profissional. São Paulo: Cortez, 1998.

As dimensões ético-políticas e teórico-metodológicas do serviço Social contemporâneo. trajetória e desafios. In: MOLINA, L. (Org.). La cuestión Social y la formación profesional en Trabajo Social en el contexto de las nuevas relaciones de poder y la diversidad latinoamericana. Buenos Aires, 2004.

Serviço Social em tempo de capital fetiche: capital financeiro, trabalho e questão social. 3. ed. São Paulo: Cortez, 2008.

O Serviço Social na cena contemporânea. In: CFESS/ABEPSS (Org.). Serviço Social: direitos sociais e competências profissionais. Brasília, 2009.

; CARVALHO, R. de. Relações Sociais e Serviço Social no Brasil: esboço de uma interpretação histórico-metodológica. São Paulo, Brasil: Celats/Cortez, 1982.

LESSA, S. Serviço Social e trabalho: do que se trata? Temporalis. ABEPSS, Brasília, ABEPSS, n. 2, p. 35-58, jul. / dez. 2000.

. Serviço Social, trabalho e reprodução. Serviço Social \& Movimento

Social. Universidade Federal do Maranhão, v.2, n. 2, p. 7-29, 2006. 
LUKÁCS, G. As bases ontológicas do pensamento e da atividade do homem. In: Temas de Ciências Humanas, v.4. São Paulo, Livraria Editora Ciências Humanas, 1978.

. Para uma ontologia do ser social II. São Paulo: Boitempo, 2013.

MARTINELLI, M. L. Serviço Social: identidade e alienação. São Paulo, Brasil: Cortez, 1989.

MARX, K. Capítulo VI Inédito de O Capital: resultados do processo de produção imediata. São Paulo: Editora Moraes, 1985.

. O Capital: crítica da Economia Política. 12. ed., livro 1, volume I e II, Rio de Janeiro: Editora Bertrand Brasil, 1994.

Para a crítica da economia política. Manuscrito de 1861-1863 (cadernos I a V) -. Terceiro Capítulo. O Capital em geral. Belo Horizonte: Autêntica Editora, 2010.

Grundrisse: manuscritos econômicos de 1857-1858: esboços da crítica da economia política. São Paulo: Boitempo, 2011.

MOTA, A. E. Cultura da crise e seguridade social. São Paulo: Cortez, 1995.

NETTO, J. P. O Serviço Social e a tradição marxista. Serviço Social e Sociedade. São Paulo, n. 30, ano X, p. 89-102, 1989.

. Ditadura e Serviço Social: uma análise do Serviço Social no Brasil pós-64. São Paulo: Cortez, 1991.

. Capitalismo monopolista e Serviço Social. São Paulo: Cortez, 1992.

. Transformações societárias e Serviço Social. Serviço Social e Socie-

dade. São Paulo, n. 50, p. 87-132, abr. 1996.

RAICHELIS, R. O assistente social como trabalhador assalariado: desafios frente às violações de seus direitos. Serviço Social e Sociedade. São Paulo, n. 107, p. 420-437, jul./set. 2011.

REVISTA Temporalis. Brasília, n. 3, ano 2, jan./jun. 2001.

RUBIN, I. I. A teoria marxista do valor. São Paulo: Polis, 1987.

SIMIONATTO, I. Gramsci: sua teoria, incidência no Brasil e influência no Serviço Social. São Paulo: Cortez/UFSC, 1995. 
TEIXEIRA, J.B.; BRAZ, M. O projeto ético-político do Serviço Social. In: CFESS/ABEPSS (Org.). Serviço Social: direitos sociais e competências profissionais. Brasília, 2009.

YAZBEK, M. C. Classes subalternas e Assistência Social. 3. ed. São Paulo: Cortez, 1993.

- Globalização, precarização do trabalho e seguridade social. Serviço

Social \& Sociedade. São Paulo, n. 56, p. 50-59, mar. 1998. 